\title{
O emprego do moodle no estágio supervisionado à docência no curso de licenciatura em química
}

\section{The use of moodle in the supervised internship for teaching in the chemistry degree course}

\author{
Marcela dos Santos Barbosa ${ }^{1 *}$, Sidilene Aquino de Farias ${ }^{2}$
}

\begin{abstract}
RESUMO
O estágio supervisionado à docência no curso de química é de suma importância para desenvolver habilidades e competências imprescindíveis para a ação docente no pós-graduando. Nesse viés, o processo de aprendizagem de diferentes métodos podem ser melhor realizados no ambiente virtual de aprendizagem Moodle. Dessa forma, com o objetivo de corroborar com a prática docente em ambientes virtuais e com a modernização de metodologias, este artigo apresenta um relato de experiência de um Estágio Supervisionado à Docência, ocorrido durante o mestrado acadêmico no Programa de Pós-graduação em Ensino de Ciências e Matemática numa disciplina semipresencial. Os resultados evidenciam que ocorreu aprendizado na utilização do Moodle, assim como a interação e criatividade da pós-graduanda no que concerne ao desenvolvimento de métodos de ensino para mediar os discentes durante o estágio.
\end{abstract}

Palavras-chave: Estágio supervisionado; Moodle; Relato de experiência

\begin{abstract}
The supervised internship for teaching in the chemistry course is extremely important to develop essential skills and competences for the teaching action in the graduate student. In this bias, the learning process of different methods can be better performed in the Moodle virtual learning environment. Thus, in order to corroborate the teaching practice in virtual environments and the modernization of methodologies, this article presents an experience report of a Supervised Internship in Teaching, which took place during the academic master's degree in the Postgraduate Program in Teaching of Science and Mathematics in a blended subject. The results show that there was learning in the use of Moodle, as well as the interaction and creativity of the graduate student regarding the development of teaching methods to mediate the students during the internship.
\end{abstract}

Keywords: supervised internship; moodle; experience report

\section{INTRODUÇÃO}

\footnotetext{
${ }^{1}$ Universidade Federal do Amazonas (UFAM). *E-mail: marceladossantosbarbosa@ gmail.com

${ }^{2}$ Universidade Federal do Amazonas (UFAM)
} 
O ambiente de Educação a Distância (EaD), conhecido como Ambientes Virtuais de Aprendizagem (AVA), é um espaço que vem sendo utilizado por diversas instituições de ensino para apoiar no processo de ensino-aprendizagem de cursos semipresenciais ou não presenciais. O AVA que será mencionado nesse trabalho é o Moodle, que vem se destacando e mudando a concepção de ensino tradicional, uma vez que o aluno se torna ativo no processo de ensino e aprendizagem.

Embora existam AVA inteligentes, chamados de Smart Learning Environments, que tornam o ensino mais flexível e adaptável de acordo com as características dos alunos (BREMGARTNER; NETTO; MENEZES, 2018), o Moodle ainda é manuseável, só funciona pelo intermédio do professor, que controla o sistema, o tempo da disponibilidade das postagens e exercícios e mantém os alunos informados sobre as datas de divulgação das atividades.

Em relação ao Estágio à Docência Supervisionado (EDS), é uma atividade curricular oriundos dos programas de pós graduação Strictu Sensu, e tem como proposta contribuir para o desenvolvimento de habilidades e competências dos mestrandos e doutorandos na carreira docente (ANGELIM et al., 2019).

O EDS propõe a reflexão da prática pedagógica na disciplina monitorada e os alunos desenvolvem uma série de atividades formativas supervisionadas pelo professor responsável pela disciplina (BARBOZA, 2013). Quando no estágio é experenciado a interação com diferentes ferramentas didáticas, como as encontradas no Moodle, que promovem a ação do aprendiz e o planejamento de diferentes métodos por parte do professor, o processo de ensino e aprendizagem se torna mais diferenciado.

Isso ocorre, sobretudo, em razão do Moodle permitir a realização de atividades como a confecção de questionários, a criação de espaços para debate, além da implementação de links de vídeos, redes sociais, artigos e demais materiais para auxiliar o discente. Assim, os alunos interagem com o sistema por meio do acesso nos arquivos disponíveis e submetendo a entrega de trabalhos e exercícios solicitados pelo professor, que poderá inclusive estabelecer tempos de submissão dos trabalhos e na disponibilidade dos arquivos.

Diante desse cenário, considera-se relevante apresentar como um EDS foi realizado com a utilização do Moodle, provocando reflexões acerca da escolha das atividades e desenvolvimento de materiais. Apresentamos as operações mais utilizadas, 
como o controle de frequência para estimular a participação, as operações mais utilizadas, além dos materiais desenvolvidos para que os alunos interagissem com o conteúdo.

No Programa de Pós Graduação em Ensino de Ciências e Matemática (PPGECIM) da Universidade Federal do Amazonas (UFAM), a disciplina EDS é obrigatória para todos os egressos e tem a duração de seis meses. O EDS permite que os pós graduandos escolham uma disciplina, preparem e ministrem aulas, sob orientação professor da disciplina.

Por tudo isso, verifica-se neste artigo um relato de experiência, realizado durante o EDS na modalidade semipresencial, mediada por práticas tutoradas na plataforma Moodle na disciplina Prática Curricular I - A, no curso de Licenciatura em Química. Também será apresentado o conteúdo programático das aulas, assim como as atividades planejadas e aplicadas nas aulas assistidas e ministradas.

Este trabalho foi estruturado da seguinte forma: Seção um foi a introdução; na Seção dois temos os trabalhos relacionados; na Sessão três encontra-se o aporte metodológico; na Seção quatro são apresentados os resultados e discussões, e por último, na Seção cinco, temos as considerações finais.

\section{TRABALHOS RELACIONADOS}

Há inúmeras pesquisas mostrando que o Moodle tem sido utilizado como ferramenta complementar e de suporte nas aulas de EaD, semipresenciais e também presenciais, em detrimento de suas aplicabilidades dispostas no AVA contribuírem para o aprendizado.

São características desse sistema a mobilidade e adaptabilidade, Para Batista et al., (2011) o Moodle pode ser acessado em qualquer dispositivo eletrônico e as atividades podem ser desenvolvidas no tempo e ritmo do usuário, que só deverá ficar atento quanto aos prazos de realização das atividades.

Outra situação, é que o Moodle tem servido de ferramenta de aprendizagem nos cursos universitários que oferecem a modalidade presencial e semipresencial. Esse AVA pode ser entendido como uma iniciativa de difusão e alteração das táticas no processo de ensino, objetivando a sua melhoria (ANGELIM et al., 2019). Nesse sentido, o processo de ensino, comumente tradicional, passa a ser transformado num sistema educativo com diferentes contextos e ferramentas de aprendizagem que promovem a participação 
coletiva, desenvolvimentos de habilidades em ambientes virtuais e de ideias para integrar a aprendizagem e a interação dialógica enquanto suporte de reflexão e argumentação.

Ademais, as inúmeras funcionalidades são cruciais para a ação discente. Sabbatini (2007) revela que o Moodle dispõe de diferentes ferramentas de avaliação, como: questionários, ensaios corrigidos, tarefas e exercícios. E ferramentas de interação como: Chat, fórum de discussão e diários. E permite que sejam colocadas páginas simples de texto, páginas em HTML, acesso a diretórios (parta de arquivos), livros eletrônicos, Wikis, glossários e acesso a arquivos com diferentes tipos de formatos (PDF, DOC, PPTX, áudio e links).

Alguns trabalhos relacionados revelam resultados positivos com o Moodle. Batista et al., (2011) experenciaram o Moodle na Pós Graduação do curso de Gestão da Tecnologia da Informação em Ambientes Educacionais, o que os fez perceber que o AVA Moodle pode ser utilizado como ferramenta complementar e que seus recursos oferecidos são eficientes no processo de ensino e aprendizagem.

Barboza (2013) fez o uso da plataforma durante o Estágio Supervisionado à Docência num curso de Licenciatura em Letras, a plataforma a fez desenvolver diferentes tipos de atividades que colaboraram com o aprendizado dos graduandos. Já Angelim et al., (2019) fizeram o uso do Moodle durante um EDS num curso de Pós Graduação em Enfermagem, a experiência foi gratificante e lhes permitiu conhece o AVA, assim como contribuir com o aprendizado de diferentes métodos pedagógicos.

Prado et al., (2012) relataram uma experiência com Moodle numa disciplina semipresencial no curso de enfermagem. Os recursos do Moodle foram bem utilizados, contribuindo com a construção de conteúdo, participação ativa dos estudantes e suporte no aprendizado na temática estudada.

Chaguri Junior et al., (2019) relataram em sua pesquisa sobre a utilização do Moodle na disciplina semipresencial de Fundamentos Filosóficos num curso de Medicina, os recursos de fórum, chat, questionário, Wiki foram bem utilizados e contribuíram com o aprendizado dos graduandos e com a criação de métodos na ação docente.

De Oliveira (2014) relatou o uso do Moodle para tutorar uma disciplina online de Língua Portuguesa, a disciplina 1 tinha o objetivo de ensinar a produção de textos científicos para a produção de artigo, os alunos trabalharam a colaboração, necessária 
para a elaboração de um artigo. Assim como Gumieiro (2018) porém a prática de produção de texto foi para graduandos do curso de Pedagogia, a disciplina era EaD.

Andrade et al., (2006) relatam uma experiência com Moodle, numa disciplina de informática no curso de Comunicação Social, o fórum foi a ferramenta utilizada para que os alunos discutissem livremente a temática abordada, também foi feito o uso do glossário, para que os alunos construíssem um repositório de informações importantes para a disciplina. As atividades disponibilizadas auxiliaram no aprendizado da disciplina e dinamizaram o processo de ensino.

\section{APORTE METODOLÓGICO}

Este artigo refere-se a um relato de experiência oriundo do EDS na disciplina Prática Curricular I-A, no período de agosto a dezembro do ano de dois mil e dezessete, realizado durante o mestrado acadêmico do PPGECIM/UFAM.

As aulas sucederam-se de forma teórica (presencial) e prática (tutorada), quando teóricas aconteciam aos sábados, quando práticas ocorriam na plataforma Moodle, no site http://ead.ufam.edu.br/dqvirtual/. Ademais, todas as aulas teóricas contaram com a presença da estagiária assim como o planejamento das atividades que seriam postadas no Moodle.

No que diz respeito ao relato de experiência, Pádua (2016, p. 84) reflete que:

O relato de experiência pode conceder ao pesquisador muitos dados significativos para o entendimento da realidade e, em tese, ofertar elementos para uma reestruturação do projeto de pesquisa. Nesse tipo de pesquisa deve se utilizar a observação sistemática ou crítica, que sucede de forma espontânea e informal. Os registros das observações a partir da prática buscaram uma elucidação da realidade e relações entre os acontecimentos que a compõem.

O aporte metodológico foi organizado em três etapas. A primeira foi a apresentação da disciplina Prática Curricular I-A e do seu conteúdo programático. A segunda etapa foi a apresentação das aulas a serem assistidas, e a terceira das aulas a serem ministradas pela graduanda. 


\section{DISCIPLINA PRÁTICA CURRICULAR I-A}

A disciplina ministrada Prática Curricular I-A, tinha uma carga horária total de sessenta horas, trinta horas destinadas para aulas presenciais e as outras trinta para práticas no Moodle. O conteúdo apresentado foi dividido em quatro unidades: unidade um, onde foram ensinados os Objetivos Educacionais e o Ensino de Ciências/Química; na unidade dois, foram apresentadas as Tendências Curriculares no Ensino de Química; a unidade três, tratou sobre o Currículo no Ensino de Ciências/Química para a Educação Básica; e a unidade quatro, abordou sobre as orientações Oficiais e as Ciências da Natureza e suas Tecnologias.

Além disso, essa disciplina foi planejada e elaborada de uma forma que componha os diversos saberes vigentes na formação inicial de professores de Química, mas especificamente os conhecimentos específicos, os didático-psicopedagógicos, como finalidades educacionais, características dos alunos, metodologias, estratégias lúdicas e interativas, compromisso ético e profissional, contexto escolar, políticas públicas, entre outros.

Shulman (1989), estudioso da educação, em suas pesquisas apresentou um conjunto de ideias para transformar diferentes tipos de conhecimentos sociais em conteúdo escolar e para permitir o entendimento do aluno, essas proposições foram chamadas por ele de Conhecimento Pedagógico de Conteúdo (CPC) ou Pedagogical Content Knowledge (PCK).

O CPC é essencial em procedimentos da aprendizagem docência. Portanto, faz-se imprescindível que na formação inicial o licenciando em Química aprenda a refletir sobre o exercício da docência, para que possa usufruir dos conhecimentos que irão sendo construídos ao longo do curso e, com isso, analisar e refletir sobre a prática educativa vivenciada em contexto real. E assim, possibilitar a transposição de conhecimentos rudimentares procedentes do senso comum, como "para saber ensinar química só precisa saber os principais conceitos e fórmulas".

O conteúdo programático da disciplina é apresentado no Quadro 1 a seguir e divide-se em: datas; aulas (carga horária e tipo); conteúdo a ser ministrado e; modalidade (presencial ou tutorada).

Quadro 1 - Cronograma das atividades 


\begin{tabular}{|c|c|c|c|c|}
\hline \multicolumn{5}{|c|}{ Conteúdo Programático/Cronograma } \\
\hline \multirow[b]{2}{*}{ Datas } & \multicolumn{2}{|c|}{ Aulas } & \multirow[b]{2}{*}{ Conteúdo } & Modalidade \\
\hline & $\begin{array}{l}\text { Carga } \\
\text { horária }\end{array}$ & $\begin{array}{l}\text { Tipo: } \\
\text { Teórica/ } \\
\text { Prática }\end{array}$ & & $\begin{array}{c}\text { Presencial/ } \\
\text { Tutorada }\end{array}$ \\
\hline \multirow[b]{2}{*}{ 05/08 } & 02 & $\mathrm{~T}$ & $\begin{array}{l}\text { Apresentação dos objetivos do curso e } \\
\text { distribuição de tarefas. }\end{array}$ & Presencial \\
\hline & 02 & $\mathrm{~T}$ & $\begin{array}{l}\text { Objetivos educacionais e ensino } \\
\text { Ciências/Química: Introdução; objetivos } \\
\text { educacionais gerais; }\end{array}$ & Tutorada \\
\hline $12 / 08$ & 02 & $\mathrm{P}$ & $\begin{array}{l}\text { Objetivos educacionais do ensino de } \\
\text { Ciências/Química; }\end{array}$ & Tutorada \\
\hline $19 / 08$ & 04 & $\mathrm{~T}$ & Função social do conhecimento químico. & Tutorada \\
\hline \multirow[t]{2}{*}{$26 / 08$} & 02 & \multirow[b]{2}{*}{$\mathrm{P}$} & \multirow{2}{*}{$\begin{array}{l}\text { Relação entre objetivos educacionais e } \\
\text { objetivos pedagógicos no Ensino de } \\
\text { Ciências/Química presentes nas escolas } \\
\text { de Educação Básica. }\end{array}$} & Presencial \\
\hline & 02 & & & Tutorada \\
\hline $02 / 09$ & 02 & $\mathrm{P}$ & $\begin{array}{l}\text { Relação entre objetivos educacionais e } \\
\text { objetivos pedagógicos no Ensino de } \\
\text { Ciências/Química presentes nas escolas } \\
\text { de Educação Básica }\end{array}$ & Tutorada \\
\hline $09 / 09$ & 02 & $\mathrm{~T}$ & $\begin{array}{l}\text { Histórico das tendências curriculares de } \\
\text { ensino de Química. }\end{array}$ & Presencial \\
\hline $16 / 09$ & 04 & $\mathrm{~T}$ & $\begin{array}{l}\text { Pressupostos teórico-metodológicos em } \\
\text { cada tendência. }\end{array}$ & Tutorada \\
\hline \multirow[t]{2}{*}{$23 / 09$} & 02 & $\mathrm{~T}$ & $\begin{array}{l}\text { Características e principais aspectos das } \\
\text { tendências; }\end{array}$ & Presencial \\
\hline & 02 & $\mathrm{P}$ & $\begin{array}{l}\text { Investigação sobre a presença das } \\
\text { tendências no currículo de formação de } \\
\text { professores de Química e na escola. }\end{array}$ & Tutorada \\
\hline $30 / 09$ & 04 & $\mathrm{P}$ & $\begin{array}{l}\text { Investigação sobre a presença das } \\
\text { tendências no currículo de formação de } \\
\text { professores de Química e na escola. }\end{array}$ & Tutorada \\
\hline $07 / 10$ & 04 & $\mathrm{~T}$ & $\begin{array}{l}\text { Aspectos históricos e político do } \\
\text { currículo. Consolidação do Ensino de } \\
\text { Ciências/Química. }\end{array}$ & Presencial \\
\hline \multirow[t]{2}{*}{$14 / 10$} & 02 & $\mathrm{~T}$ & \multirow{2}{*}{$\begin{array}{l}\text { Transposição didática: conhecimento } \\
\text { químico e conhecimento escolar. }\end{array}$} & \multirow{2}{*}{ Tutorada } \\
\hline & 02 & $\mathrm{P}$ & & \\
\hline $21 / 10$ & 02 & $\mathrm{P}$ & $\begin{array}{l}\text { Transposição didática: conhecimento } \\
\text { químico e conhecimento escolar. }\end{array}$ & Tutorada \\
\hline \multirow[t]{2}{*}{$04 / 11$} & 02 & $\mathrm{P}$ & \multirow{2}{*}{$\begin{array}{l}\text { Análise de conteúdos de científicos e } \\
\text { conteúdos escolares. }\end{array}$} & Presencial \\
\hline & 02 & $\mathrm{P}$ & & Tutorada \\
\hline $11 / 11$ & 04 & $\mathrm{P}$ & $\begin{array}{l}\text { Análise de conteúdos de científicos e } \\
\text { conteúdos escolares. }\end{array}$ & Tutorada \\
\hline \multirow[t]{2}{*}{$18 / 11$} & 02 & \multirow{2}{*}{$\mathrm{T}$} & \multirow{2}{*}{$\begin{array}{l}\text { Orientações Curriculares Nacionais para } \\
\text { o Ensino Médio. }\end{array}$} & Presencial \\
\hline & 02 & & & Tutorada \\
\hline
\end{tabular}




\begin{tabular}{|c|c|c|l|c|}
\hline 25/11 & 04 & $\mathrm{~T}$ & $\begin{array}{l}\text { Princípios formativos: contextualização } \\
\text { e interdisciplinaridade. }\end{array}$ & Tutorada \\
\hline $02 / 12$ & 04 & $\mathrm{P}$ & $\begin{array}{l}\text { Reflexo das orientações oficiais na } \\
\text { prática educativa em Química: conflitos } \\
\text { e inobservância. }\end{array}$ & Tutorada \\
\hline $09 / 12$ & 02 & $\mathrm{~T}$ & Avaliação Final - Todo conteúdo. & Presencial \\
\hline
\end{tabular}

Fonte: Elaborado pelas autoras

A disciplina Prática Curricular I-A constitui o alicerce estruturante da matriz curricular do Curso de Licenciatura em Química, vigente no Projeto Pedagógico do Curso, nomeado Didático-Psicopedagógico.

Esse eixo foi organizado de modo a atender a Resolução CNE/CP No 002/2015, publicada em 03/07/2015, que denomina que todo curso de licenciatura deverá ter quatrocentas horas dedicadas a Prática Como Componente Curricular (CARVALHO, 2017; GEHRKE; MALLAT, 2018). Portanto as disciplinas devem viabilizar que o graduando dos cursos de licenciatura esteja ciente da concepção de prática como uma extensão do conhecimento, e que é necessária para se trabalhar a reflexão, a comunicação, e o desenvolvimento de habilidades e competências que se relacionam com a atividade profissional (VIEIRA; DE ARAÚJO; SLONGON, 2020).

Entende-se que para ser professor é necessária formação adequada que supere a divisão entre teoria e prática (prática educativa). Para superar essa divisão é preciso que o licenciando compartilhe junto com os professores universitários a responsabilidade pela sua aprendizagem, dedicando-se as leituras, participando das atividades, empenhando-se para que tenha uma formação de qualidade, para que futuramente possam fazer a diferença e contribuir com a melhoria da qualidade do ensino de Química.

\section{AULAS ASSISTIDAS}

As aulas ditas como assistidas foram assim nomeadas porque foram observadas pela mestranda, ministradas e planejadas pela professora orientadora. O cronograma dessas aulas está disponibilizado no Quadro 2 a seguir e foi organizado em: hora e unidade a ser ensinada na aula; mês da aplicação das aulas; dias das aulas e descrição dos conteúdos que foram apresentados. 
Quadro 2 - Cronograma das atividades

\begin{tabular}{|c|c|c|c|}
\hline Hora/Aula & Mês & Dias & Descrição de Conteúdo \\
\hline $\begin{array}{c}\text { 14h/Unidade } \\
\text { I }\end{array}$ & Ago & $\begin{array}{c}05 / 12 / 1 \\
9 / 26\end{array}$ & $\begin{array}{l}\text { Objetivos educacionais e ensino Ciências/Química: } \\
\text { Introdução; objetivos educacionais gerais; } \\
\text { Função social do conhecimento químico; } \\
\text { Relação entre objetivos educacionais e objetivos pedagógicos } \\
\text { no Ensino de Ciências/Química presentes nas escolas de } \\
\text { Educação Básica; }\end{array}$ \\
\hline $\begin{array}{l}\text { 16h/Unidade } \\
\text { II }\end{array}$ & Set & $\begin{array}{l}02 / 09 / 1 \\
6 / 23 / 30\end{array}$ & $\begin{array}{l}\text { Relação entre objetivos educacionais e objetivos pedagógicos } \\
\text { no Ensino de Ciências/Química presentes nas escolas de } \\
\text { Educação Básica; } \\
\text { Histórico das tendências curriculares de ensino de Química; } \\
\text { Pressupostos teórico-metodológicos em cada tendência; } \\
\text { Características e principais aspectos das tendências; } \\
\text { Investigação sobre a presença das tendências no currículo de } \\
\text { formação de professores de Química e na escola. }\end{array}$ \\
\hline \multirow[t]{2}{*}{$\begin{array}{l}\text { 20h/Unidade } \\
\text { IV }\end{array}$} & Nov & $\begin{array}{c}4 / 11 / 18 \\
/ 25\end{array}$ & $\begin{array}{l}\text { Análise de conteúdos de científicos e conteúdos escolares; } \\
\text { Orientações Curriculares Nacionais para o Ensino Médio: } \\
\text { Orientações Curriculares Nacionais para o Ensino Médio; } \\
\begin{array}{l}\text { Princípios formativos: contextualização } \\
\text { interdisciplinaridade; }\end{array}\end{array}$ \\
\hline & Dez & 02/09 & $\begin{array}{l}\text { Reflexo das orientações oficiais na prática educativa em } \\
\text { Química: conflitos e inobservância. }\end{array}$ \\
\hline
\end{tabular}

Fonte: Elaborado pelas autoras

\section{AULAS MINISTRADAS}

Como estratégia de adaptação e interação com o Moodle ao longo do EDS, foi escolhido a unidade três para ser de responsabilidade da mestranda. Assim, foram definidas dez horas de aulas teóricas para serem ministradas, além do planejamento dos materiais para leitura e atividades a serem realizadas pelos graduandos. O cronograma das aulas encontra-se no Quadro 3 a seguir.

Quadro 3 - Cronograma das atividades

\begin{tabular}{|c|c|c|lr|}
\hline Hora/Aula & Mês & Dias & \multicolumn{1}{|c|}{ Descrição de Conteúdo } \\
\hline $\begin{array}{c}\text { 10h/Unidade } \\
\text { III }\end{array}$ & Out & $7 / 14 / 21$ & $\begin{array}{l}\text { Aspectos históricos e político do currículo. Consolidação do } \\
\text { Ensino de Ciências/Química; } \\
\text { Transposição didática: conhecimento químico e e } \\
\text { conhecimento escolar; }\end{array}$ \\
\hline
\end{tabular}

Fonte: Elaborado pelas autoras

Às aulas ministradas contaram com atividades para fixação dos conteúdos. Para a aula um (Aspectos Históricos e Político do Currículo) foi desenvolvido um quadrinho histórico para os discentes preenche-lo. Para a aula dois (Temática Consolidação do 
Ensino de Ciências/Química) e aula três (Transposição Didática: Conhecimento Químico Escolar) foi orientado aos graduandos que fizessem um mapa conceitual.

\section{RESULTADOS E DISCUSSÃO}

Serão apresentados nesta sessão o procedimento de ensino e aprendizagem, assim como as atividades realizadas pela mestranda nas aulas assistidas e em suas aulas ministradas durante o EDS.

Ademais, na disciplina Prática Curricular I-A haviam sessenta alunos matriculados, mas apenas quarenta e quatro tinham uma frequência regular de participação nas aulas presenciais e no Moodle.

\section{PROCEDIMENTO DE ENSINO E APRENDIZAGEM DAS AULAS}

As aulas tutoradas no Moodle apresentaram uma série de recursos lúdicos e didáticos, diferente do que é visto em aulas tradicionais, tornando os alunos ativos no processo de aprendizagem. Assim, foram disponibilizados aos graduandos recursos como: chats; fórum de discussão; questionários; glossários; atividade com hipertextos; material didático para auto estudo; diário de leitura; atividade de produção textual; pesquisa de avaliação; fontes de leitura; links de vídeos do YouTube e áudios. A Figura 1 a seguir apresenta uma imagem do ambiente do Moodle (printada durante o período de EDS).

Figura 1 - Imagem da área de postagem das atividades no Moodle 


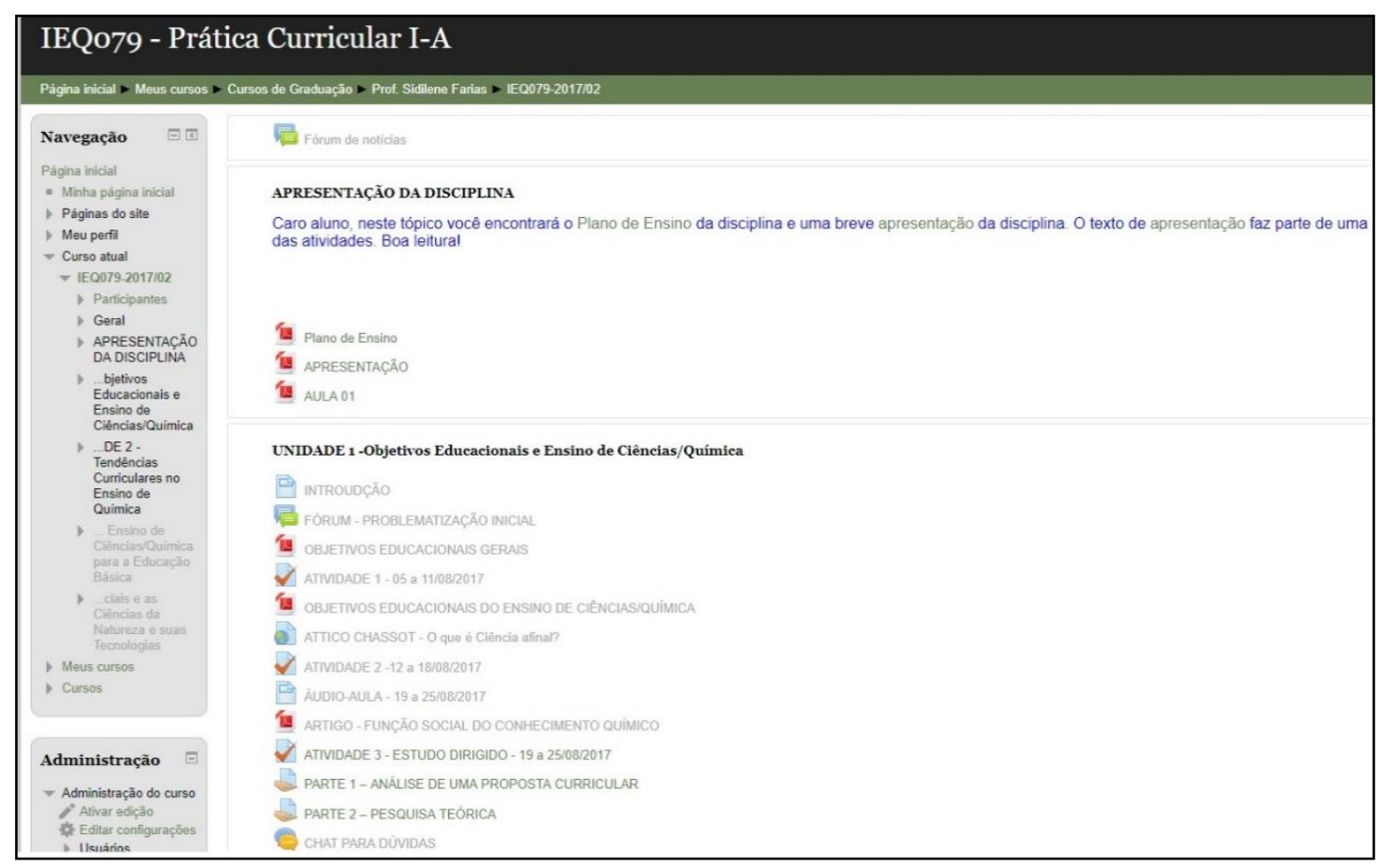

Fonte: Elaborado pelas autoras

Em todas as semanas eram postadas atividades, uma atividade por semana para ser exato. As atividades disponibilizadas após as aulas presenciais valiam ponto, já as postadas nas semanas que não haviam aulas presenciais valiam presença. E assim era feito o controle da frequência. Além disso, existia um grupo no WhatsApp da disciplina, em que eram emitidos comunicados e avisos referente as atividades. Aos alunos que não tinham celular ou computador em casa foi disponibilizado acesso a uma sala de informática no Departamento de Química, localizado no Instituto de Ciências Exatas (ICE)/UFAM.

Quanto a avaliação, os graduandos eram avaliados por meio das análises das atividades solicitadas, sendo atribuída uma nota de zero a dez. A correção era necessária para verificar se havia ocorrido leitura e/ou pesquisa do conteúdo proposto. Quando a atividade valia presença também era atribuído nota, os alunos com notas acima de sete recebiam presença.

No final da disciplina foi realizada uma prova referente a todo o conteúdo estudado ao longo do semestre, e para auxiliar no estudo dos alunos foi disponibilizado no Moodle um resumo.

ATIVIDADES REALIZADAS NAS AULAS ASSISTIDAS 
As aulas assistidas foram as unidades um, dois e quatro, dada a organização serão mostradas as práticas nessa ordem.

A princípio na unidade um foi solicitado a mestranda a participação no fórum para subsidiar as respostas dos alunos, as questões discutidas foram "Qual a função da escola? A quais propósitos as escolas servem ou devem servir? Quais conhecimentos são mais importantes? O que significa conhecer algo?”.

Outra ação foram os momentos de orientação no Chat do Moodle, necessários para tirar dúvidas das atividades passadas e dos conteúdos ensinados. O Chat era disponibilizado uma vez por semana, nos sábados, quando não haviam aulas presenciais. Essa ferramenta foi utilizada até a unidade dois. O slogan do Chat encontra-se na Figura 2 abaixo.

Figura 2 - Slogan de apresentação do Chat disponível no Moodle

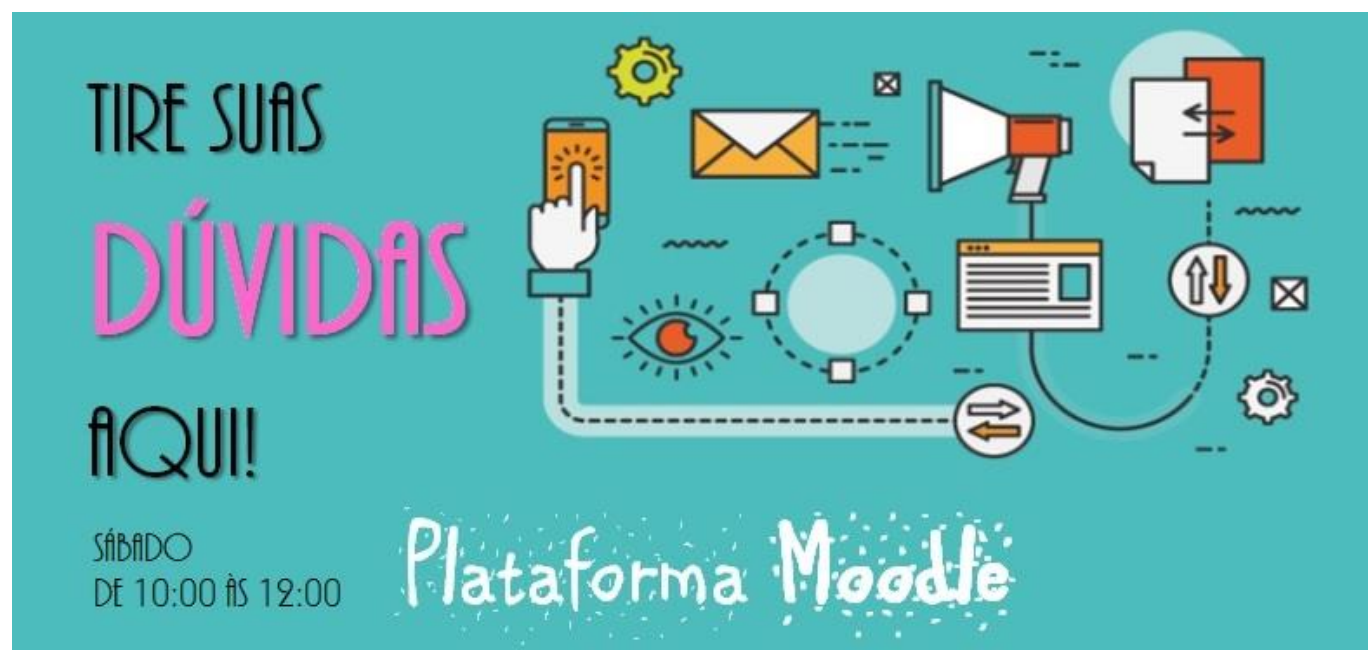

Fonte: Elaborado pelas autoras

Para finalizar as ações realizadas na unidade um tivemos a correção da atividade um, que resume-se na criação de um glossário, com as palavras: senso comum, científico, dicotomia e prática educativa; realizar um resumo sobre Bloom e seu trabalho, e responder duas às perguntas: qual verbo é para o professor e qual é para o aluno? a qual domínio está relacionado objetivo específico? O glossário, resumo e questões foram corrigidos no Moodle, juntamente com a professora orientadora, para aprendizado e adaptação com o sistema. Como resultado da correção, apenas vinte e quatro alunos realizaram as atividades, todos apresentaram bons resultados.

Ainda na unidade um, outras atividades foram solicitadas, como: questionário que abordava sobre objetivos educacionais, Francis Bacon, Attico Chassot e Hodson; estudo 
dirigido com doze questões; e correção de uma pesquisa teórica o Programa Nacional do Livro Didático. Porém, em detrimento da falta de habilidades com o sistema do Moodle, por parte da mestranda, apenas a professora orientadora corrigiu essas atividades.

Salvador e Piton (2006) advertem que o uso de novas tecnologias no processo de ensino prevê o preparo dos usuários diante da nova tecnologia. As novas ferramentas exigem dos sujeitos do processo adaptação na usabilidade, da ferramenta e do saber a ser expandido ou construído durante o decorrer da disciplina.

Para a unidade dois, além dos momentos de orientação realizados no Chat, foi realizado uma monitoria durante a primeira aula da unidade dois, para observar e auxiliar na organização de uma atividade em grupo, onde os alunos tiveram que formar equipes com três integrantes, e escolher um representante para argumentar sobre um trecho do livro de Pozo e Goméz, relacionados com as tendências no ensino, quarenta e quatro alunos participaram dessa atividade.

Dando continuidade à atividade, após a aula as equipes tiveram que acessar o WIKI do Moodle e desenvolver uma síntese sobre as características e aspectos das tendências no ensino de ciências/química. Foi orientado que eles fizessem a atividade no Word e depois submetessem no Moodle, onde ativariam os links. A atividade foi construtiva, os alunos acrescentaram imagens, esquemas e links de arquivos relacionados com o tema. Dos quarenta e quatro alunos que estavam organizados em equipes, quarenta e dois fizeram a atividade e trinta e quatro desenvolveram textos bem fundamentados e criativos.

Também foi cumprido o desenvolvimento de uma aula prática sobre as Tendências Curriculares no Ensino de Química, tendo como base os estudos apresentados por Myriam Krasilchik. Essa aula foi preparada no PowerPoint, onde do mesmo foi gerado um vídeo (formato mp4) e colocado no YouTube. O link do vídeo foi disponibilizado na plataforma Moodle, essa aula pode ser assistida pelo seguinte link: https://www.youtube.com/watch?v=5pelYULtDV8\&t=2s. Como atividade do conteúdo do vídeo foi orientado que os alunos criassem um quadro teórico histórico. Como resultado, quarenta e dois alunos entregaram a atividade, mas apenas os materiais de trinta e oito alunos foram aceitos e, dentre esses, dezenove trabalhos foram bem confeccionados e argumentados.

Para unidade quatro houve apenas correção de atividades realizadas no Moodle. Foram corrigidos resumos submetidos no Moodle, que tratavam sobre um vídeo do 
Programa "Sala Debate", do canal Futura, sobre a Base Nacional Curricular (BNCC). Apenas dezesseis alunos entregaram o resumo e todos esses souberam analisar e pontuar os conceitos mais importantes.

Também foi corrigido uma atividade onde os alunos tiveram que analisar uma sequência didática retirado do artigo "O milho das comidas típicas juninas: uma sequência didática para a contextualização sociocultural no ensino de Química”, da revista Química Nova a Escola; seguido da correção de questões de análise sobre o artigo. Assim, trinta e três alunos entregaram a sequência didática, e a analisaram bem, além de responderem corretamente as questões de análise.

A correção da prova ficou sob responsabilidade da professora orientadora.

\section{ATIVIDADES REALIZADAS NAS AULAS MINISTRADAS}

Na Unidade três os conteúdos a serem trabalhados eram: aspectos históricos e político do currículo (conteúdo um); consolidação do Ensino de Ciências/Química (conteúdo dois); transposição didática: conhecimento químico e conhecimento escolar (conteúdo três).

Para o conteúdo um a aula teórica aconteceu em sala de aula e ela também foi disponibilizada no $\quad$ Youtube, com link: https://www.youtube.com/watch?v=1rshzwIU3NM . A aula foi adaptada do artigo do Attico Chassot "Uma História da Educação Química Brasileira”. Para atividade foi pedido que os alunos realizassem a impressão do quadrinho, que foi disponibilizado no Moodle, e pelas características apresentada nas aulas assistidas eles tiveram que preencher as lacunas vazias, usando a criatividade. O quadrinho foi desenvolvido com o auxílio do Power Point e Word e encontra-se na Figura 3 abaixo.

Figura 3 - Imagem do quadrinho histórico disponibilizado aos alunos 


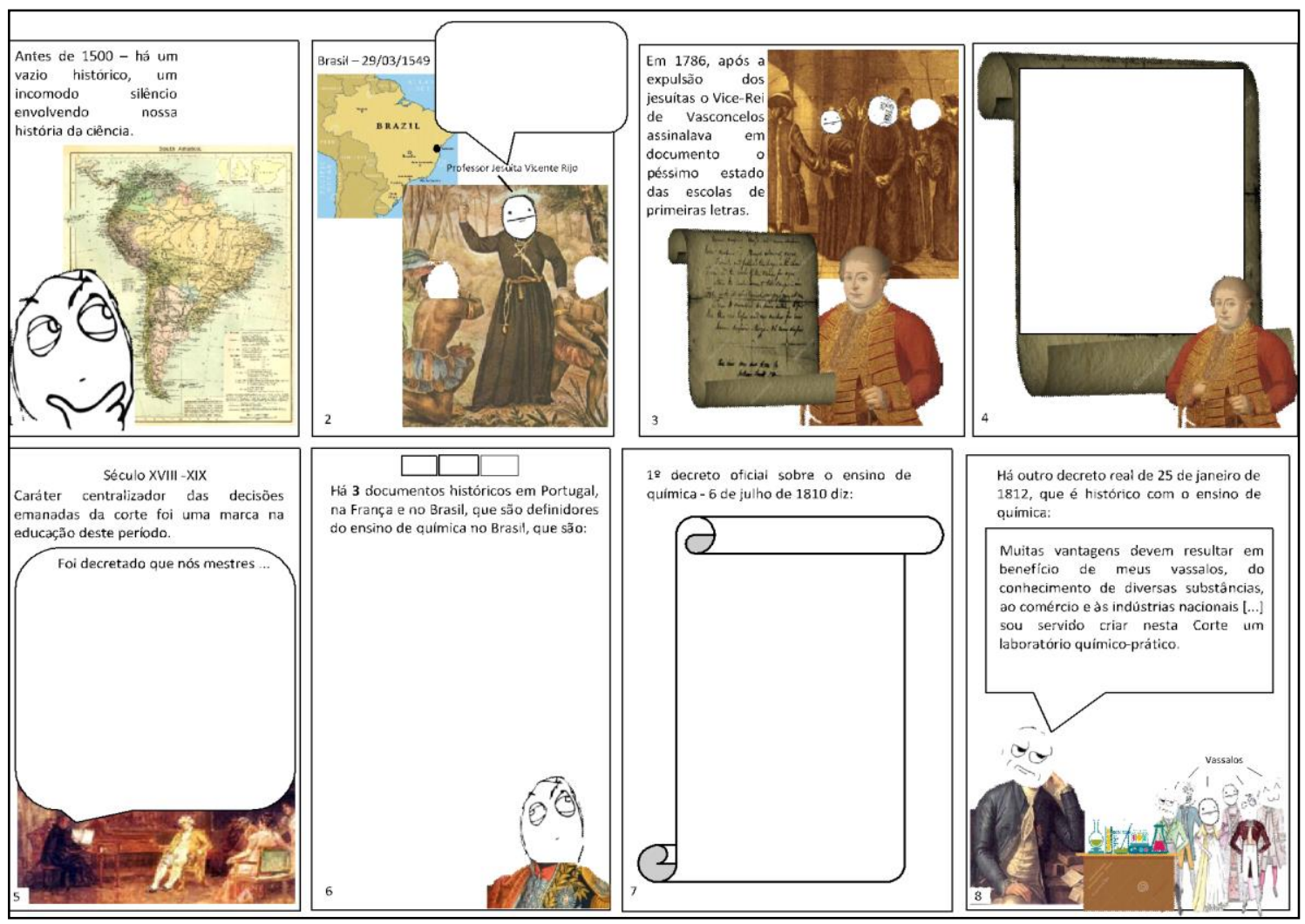

Fonte: Elaborado pelas autoras

A atividade foi realizada por quarenta e um alunos e todos apresentaram um bom desempenho textual e criativo.

Para o conteúdo dois e três foram realizadas aulas teóricas em sala de aula. No conteúdo dois foi abordado como ocorreu a consolidação do ensino de ciências no Brasil, a aula foi baseada no livro Currículo e Epistemologia, de Alice Lopes. Já no conteúdo três foi abordado sobre o processo de transposição didática, e um pouco sobre a interdisciplinaridade.

A atividade pedida teve relação com os dois conteúdos dois e três. Os alunos tiveram que relacioná-los e elaborar um mapa conceitual, que poderia ser feito no PowerPoint, Paint, Word ou softwares específicos, e ser submetido no Moodle.

Para melhor desenvolvimento da atividade foram disponibilizados materiais para leitura no Moodle, referente ao conteúdo das aulas, e também foi criado um vídeo no PowerPoint sobre Mapa Conceitual, que posteriormente foi disponibilizado no Moodle. O vídeo pode ser acessado no link https://www.youtube.com/watch?v=XA41XzaJ9Co\&t=11s . Esse vídeo foi adaptado do artigo "Mapas Conceituais e Aprendizagem Significativa, de Marco Antônio Moreira". 
Assim, como resultado de participação, trinta e cinco alunos entregaram a atividade e todos esses receberam um feedback positivo.

\section{CONSIDERAÇÕES FINAIS}

Os recursos disponíveis no Moodle possuem características que permitem a interação e colaboração, que quando somadas a um ambiente de ensino semipresencial estimulam o processo de ensino e aprendizagem, que por sua vez tornam os alunos mais participativos.

A partir do mapeamento de pesquisas relacionadas com estágio supervisionado e atividades que envolvessem o uso de AVA, testes e manuseio do sistema Moodle, foi possível planejar a aula assistida, na Unidade dois, sobre tendências curriculares e, como seriam as aulas e as atividades dos graduandos nas aulas ministradas na Unidade três. A partir de pesquisas que envolvessem criatividades e ação discente foram produzidos o quadrinho histórico e a atividade com mapa conceitual.

Os resultados apontam que a utilização da plataforma Moodle no estágio supervisionado à docência contribuiu com o envolvimento de novos recursos e aprendizado na execução de vídeos no PowerPoint, submissão dos mesmos no YouTube e compartilhamento de links; na criação de quadrinhos; interação no Chat e fórum; desenvolvimento de textos no Wiki e questionários no Moodle.

Tendo em vista os fatos apresentados, verifica-se a necessidade de explorar o Moodle em outros tipos de temáticas no curso de química, principalmente em disciplinas experimentais onde os estudantes comumente formam duplas, desenvolvem os procedimentos experimentais e entregam relatórios. No Moodle eles poderiam compartilhar nos fóruns sobre os cálculos realizados e as observações das reações testadas, e o professor poderia disponibilizar Links de vídeos sobre a prática, antes dela ser realizada.

Isto posto, essa pesquisa beneficiou o desenvolvimento de métodos didáticos criativos, na investigação dos recursos disponibilizados pelo AVA Moodle, assim como na colaboração de ações didáticas que tornam o aluno mais ativo, que se deu durante o estágio supervisionado. Essa ação pedagógica pode ser inserida sem grandes 
complicações em Instituições de Ensino semipresenciais, viabilizando a utilização do Moodle e estimulando a autonomia e proatividade nos alunos.

\section{REFERENCIAS}

ANGELIM, R. C. de M.; BRANDÃO, B. M. G. de M.; PEREIRA, V. M. A. O.; FREIRE, D. de A.; ABRÃO, F. M. da S. Educação à distância no ensino superior: relato de experiência em estágio de docência. Revista de Enfermagem do Centro-Oeste Mineiro, v. 9, 2019.

ANDRADE, A. L. L.; BRITO, M. S. da S.; ALVES, L. R. G. Ambiente Moodle como apoio ao Ensino em Publicidade e Propaganda. In: XXXIX Congresso Brasileiro de Ciências da Comunicação - UnB. 2006. Anais do Congresso Brasileiro de Ciências da Comunicação. 2006.

BARBOZA, A. C. C. Novas tecnologias na formação inicial docente: o moodle, como recurso de apoio ao estágio. Revista Brasileira de Pesquisa sobre Formação de Professores, v. 5, n. 9, p. 81-95, 2013.

BATISTA, A; DE OLIVEIRA, C. A.; HENCK, J.; DA SILVA, T. A.; NUNES, Y. Uma experiência educativa na Pós-Graduação - O uso do Moodle no Curso de Gestão da Tecnologia da Informação em Ambientes Educacionais. In: VIII SIMPÓSIO DE EXCELÊNCIA EM GESTÃO E TECNOLOGIA (SEGET). 2011, Resende, Rio de Janeiro. Anais do VIII Simpósio de Excelência em Gestão e Tecnologia (SEGeT). Resende, Rio de Janeiro, 2011.

BEZERRA, A. M. de C. A Formação de professores no Brasil: um estudo das diretrizes curriculares nacionais para a formação inicial e continuada dos professores. 2017. 177f. Orientador: PORTO, Rita de Cassia Cavalcanti. Dissertação (Mestrado em Educação) - Programa de Pós Graduação em Educação, Universidade Federal da Paraíba, João Pessoa, 2017.

BREMGARTNER, V.; NETTO, J. F.; DE MENEZES, C. Explorando arquiteturas pedagógicas recomendadas por meio de agentes e ontologia de modelo do aluno em ambientes virtuais de aprendizagem. In: BRAZILIAN SYMPOSIUM ON COMPUTERS IN EDUCATION. 2015. Anais do Simpósio Brasileiro de Informática na Educação (SBIE). 2015.

CHAGURI JUNIOR, J. C.; DE OLIVEIRA, C. M.; AZEVEDO, E. T.; SILIPRANDE, M. D.; FONTES, J. J. R. Utilização do ava moodle e suas contribuições no processo de ensino-aprendizagem: um relato de experiência da plataforma em uma disciplina de ciências humanas voltada à saúde. Revista Transformar, Itaperuna, RJ, v. 13, n. 2, 2019. 
DE OLIVEIRA, D. A produção de texto no ambiente online de aprendizagem moodle: relato de experiência. Texto Livre: Linguagem e tecnologias, v. 7, n. 1, p. 1-13, 2014.

GEHRKE, M.; MALLAT, J. D. As políticas educacionais e a formação inicial de professores: a didática na resolução 002/2015. Revista Contrapontos, v. 18, n. 2, p. 89$104,2018$.

GUMIEIRO, A. H. A disciplina de laboratório de textos científicos: experiência no ambiente virtual de aprendizagem ava-moodle. In: SEMINÁRIO FORMAÇÃO

DOCENTE: INTERSECÇÃO ENTRE UNIVERSIDADE E ESCOLA. V. 2, n. 2, 2018. Anais do Seminário Formação Docente: Intersecção entre Universidade e Escola, 2018.

PRADO, C.; SANTIAGO, L. C.; SILVA, J. A. M.; PEREIRA, I. M.; LEONELLO, V. M.; OTRENTI, E.; PERES, H. H. C.; LEITE, M. M. J. Ambiente virtual de aprendizagem no ensino de Enfermagem: relato de experiência. Revista Brasileira de Enfermagem, Brasília, v. 65, n. 5, 2012.

SABBATINI, R. M. E. Ambiente de ensino e aprendizagem via Internet: a Plataforma Moodle. Instituto EduMed, v. 7, 2007.

SALVADOR, J. A.; PITON, J. O Moodle como ferramenta de apoio a uma disciplina presencial de Ciências Exatas. In: CONGRESSO BRASILEIRO DE EDUCAÇÃO EM ENGENHARIA (COBENGE). Passo Fundo, 2006. Anais do Congresso Brasileiro de Educação em Engenharia (CBEE). Passo Fundo, 2006.

VIEIRA, M. M. M.; DE ARAÚJO, M. C. P.; SLONGO, I. I. P. Formação docente e educação profissional: análise a partir de Shulman e Fleck. Roteiro, v. 45, p. 1-28, 2020. 